\title{
correspondence
}

\section{The Loch Ness Monster}

SIR,- In their recent article entitled "Naming the Loch Ness Monster" (Nature, December 11) Scott and Rines propose formal generic and specific names for a rhomboidal object photographed in Loch Ness. They fail, however, to demonstrate with any conviction that the object is animate, that it shares anything with the later photograph showing two very differently shaped images, or that there is any basis whatever for their suggestion that it represents a species of reptile.

One of the great achievements of eighteenth century zoologists was to devise a disciplined system for the description and naming of animals, one result of which was effectively to distinguish between the real and the mythical animals of earlier writings. The code of nomenclature that has been developed over the succeeding years has been very carefully designed to adjudicate only with regard to the choice of names, thereby avoiding any restriction of freedom in the interpretation of zoological evidence. The onus is therefore on authors and editors to maintain standards of description and rational argument to prevent a return to the days of uncritical mythology.

Readers of Nature might reasonably expect an article presenting and interpreting original taxonomic data to have been subjected to the normal refereeing process. The evidence presented for the existence of Nessiteras rhombopteryx as a new species of animal falls far short of any normal standards expected in taxonomic zoology, even allowing for the preliminary nature of the report. No details are given of the 'optical data' by which the sizes of the objects were determined, nor of the technique by which the first two photographs were determined, nor of the technique by which the first two photographs were 'computer-enhanced'. No mention is made of controls showing how familiar objects appear on film and sonar traces under the same conditions. These will presumably be included when the observations are published in more detail, but meanwhile it is inconceivable that the application of a name in these circumstances can serve the authors' objective of promoting the conservation of any large animal that might subsequently be found in Loch Ness.

Biologists daily encounter pheno- mena that they cannot identify or explain. It happens every time a field ornithologist fails to identify a distant bird. He will normally prefer to explain his failure in terms of the limitations of his expertise, the poor atmospheric conditions or the extreme distance, rather than jump to the conclusion that it must be an undescribed species of bird. This analogy is very relevant to a great diversity of so-called unexplained phenomena in Loch Ness.

Zoological taxonomy and scientific publication in Britain have both achieved high reputations. It is a pity to jeopardise these reputations for no good cause. It would be an exciting day for all zoologists if convincing proof were to be produced of a new large animal in the zoologically best explored country on Earth. This paper is unlikely to persuade the scientific community that that day has arrived although it may well serve to mislead the layman into believing that it has.

\section{Department of Zoology,} Gordon B. Corbet

\section{British Museum (Natural History),} London SW7, UK

\section{Sir Peter Scott replies:}

G. B. Corbet. referring to a rhomboidal object shown in two photographs in the article "Naming the Loch Ness Monster", claims that its authors "fail to demonstrate with any conviction that the object is animate" by which no doubt he means that he is not convinced. Others with equal claims to scientific objectivity have expressed an opposite view, being impressed by the slight difference in the configuration and the orientation of the flipper shown by the pictures, taken one minute apart by a fixed camera on the bottom, which clearly shows that the structure cannot be rigid.

Dr Corbet chooses to ignore the simultaneous sonar evidence with its clear indication that moving objects of large size were present at the time the photographs were taken. He says we have failed to demonstrate "that there is any basis whatever for the suggestion that it represents a species of reptile". We explain that we believe the flipper belongs to a vertebrate animal and that no known aquatic mammal has such a limb. It has not been possible to attribute the shape to any known fish or amphibian; on the other hand, the shape conforms rather closely with the limbs of certain fossil reptiles. In spite of his analogy which refers to "an undescribed species of bird", it seems unlikely that Dr Corbet would prefer to attribute the Loch Ness Monster to that class. The actual quote from the article is "the inclination is to view it as reptilean".

The objective of the paper was quite clearly stated in the preamble: "Better to be safe than sorry; a name for a species whose existence is still a matter of controversy among many scientists is preferable to none if its protection is to be assured". I do not know what particular expertise Dr Corbet may have for asserting that the objective will not be achieved. Meanwhile it seems sad that he is working so hard to prevent it.

SIR,-The publication of Scott and Rines and the photographs in the national press indicate that there may be a plesiosaur-like reptile inhabiting Loch Ness. It is exceedingly difficult to envisage how a former tropical marine reptile could endure the cold waters and harsh environment provided by a small lake in Scotland. Since Loch Ness did not exist until some 12,000 years ago, one is faced with the problem of the survival of 'Nessiteras' for a period of 64 million years in a world where its former ecological niche had been occupied by modern cetaceans and pinnipeds.

A certain amount of research on the functional anatomy of plesiosaurs has been undertaken and the results widely reported*. There were two major types: the long-necked which fed on fish in the surface waters, and the streamlined large-headed forms which fed on cephalopods and were capable of diving to depths of $300 \mathrm{~m}$. The postulated shape of 'Nessiteras' is reminiscent of the non-diving surface living variety; the postulated behaviour is of the large-headed short-necked forms. The evolutionary history of both groups of plesiosaurs can be traced for a period of 150 million years with very minor changes being recorded. It is inherently improbable that from such a stock this strange mixture of both groups would suddenly emerge.

The three key pieces of photographic evidence, which purport to show the neck and part of the body, the right hind flipper and the head, deserve to be analysed in the context of the accumulated knowledge of both living 
and extinct aquatic reptiles and other water-dwelling air-breathers. The only way that the neck and body picture could be restored to form a plesiosaur would be to cover a skeleton with skin, but with the musculature reconstructed a different shape would be produced. The appearance of a truncated 'limb' and its negative on the opposite side of the 'body', together with other rectangular areas, would seem to exclude any possibility of this structure being reptilian.
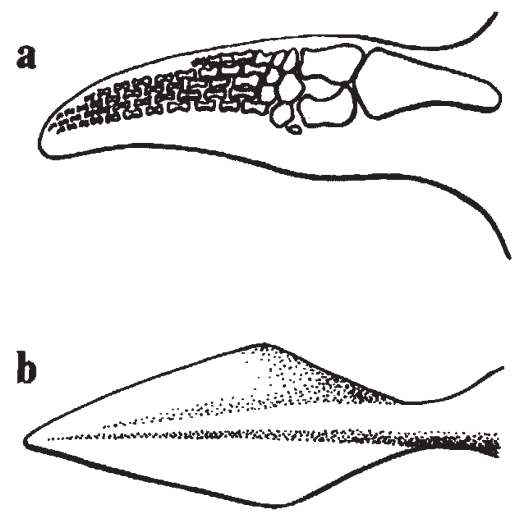

Fig. a Hydrofoil limb of Plesiosaurus to show extent of soft tissues (after Robinson 1975)

Fig. b Oar forelimb of 'Nessiteras' to show axial 'skeleton' (after Scott and Rines 1975).

The correct shape of plesiosaur flippers is rarely illustrated, but it has been known since Dames described skin impressions in 1895 . The bones were situated along the leading edge with a tapering fleshy trailing edge; the plesiosaur limb was hydrofoilshaped (Figs $a$ and b). The limbs of plesiosaurs functioned in the same way as those of marine turtles, penguins and sea lions. The type of fin described by Scott and Rines is not known to exist in any marine vertebrate to our knowledge. It is not a hydrofoil but instead is oar-shaped. There is a central axis and the distal end tapers to a point thus reducing drag. It is inconceivable that an animal with efficient hydrofoil limbs should dispense with them for inefficient oars.

The heads of marine reptiles have their nostrils situated immediately in front of the orbits (the crocodiles are the exception to this but they have achieved the same functional end by evolving a secondary palate). Furthermore, the heads are streamlined. In contrast to this, the photograph of the Loch Ness head has terminal nares with the nasal region being clearly marked off from the orbital by a pronounced ridge or step. There even appear to be horns growing from the frontal region. There is no hint among any group of reptiles of such quasimammalian contours.

The evidence claimed to establish the existence of an aquatic reptile 'Nessiteras rhombopteryx' allows of an alternative and more logical interpretation.

The 'body-neck' photograph could be of the prow or stern of a Viking ship; the positive and negative projections would be transverse cross-beams of the hull; the longitudinal rectangle would be one of the main planks. It is perhaps worth noting that there are records of Viking raids on ancient settlements in the region of Loch Ness, for example Iona.

Mr Sheridan has already pointed out (reported in The Times) the similarity of the $2 \mathrm{~m}$ long right hand fin to the steering rudder of Viking ships, which is always situated at the starboard stern (posterior right-hand side). Finally the head photograph is exceedingly similar to the dragon heads with which the Vikings embellished the prows of their vessels (and royal furniture). The Loch Ness head would appear to be generically related to the Oseberg head in Oxenstierna's The Norsemen.

The features attributed to the new taxon Nessiteras rhombopteryx are inconsistent with the anatomy and inferred functioning of any group of extinct reptile. The conclusion seems inescapable: Scott and Rines have discovered the remains of a Viking ship and have mistakenly interpreted them in terms of a living organism.

\section{B. Halstead \\ P. D. GORIUP \\ J. A MIDDLETON}

Departments of Geology and Zoology, University of Reading, UK

* Watson, D. M. S., Proc. zool. Soc. Lond., 885 (1924) Tarlo, L. B., Palaeontology, 1, 193 (1958); ibid., 2, 39 (1959); New Scientist, 1414 (1960); Newman, B. H. and Tarlo, L. B... Animals, 10 (2), 61 (1967); Halstead L. B., The Pattern of Vertebrate Evolution, 132 (Oliver and Boyd, Edinburgh, 1969); Halstead, L. B., and Middleton, J. A.. Bare bones-an exploration in art and science, 29 (Oliver and Boyd, Edinburgh, 1972): Robinson, J. A., N. Jb. Geol. Paläont. Abh., 149, 286 (1975): Halstead, L. B., The evolution and ec
the dinosaurs, 68 (Peter Lowe, London, 1975).

\section{Sir Peter Scott replies:}

Your correspondents Halstead, Goriup and Middleton argue interestingly that plesiosaurs were either long-necked and lived in shallow water eating fish, or short-necked and dived to $300 \mathrm{~m}$ to catch squids. They claim that the behaviour of Nessiteras (of which we know very little) living in a loch that is $300 \mathrm{~m}$ deep, but being long-necked, is "a strange mixture of both groups" and therefore "inherently improbable." But in many animal orders whose evolution displays adaptive radiation we find primitive types surviving among the more advanced. To discover features of two known groups combined in one species does not necessarily postulate reticulate evolution.

I agree with your correspondents when they say "it is inconceivable that an animal with efficient hydrofoil limbs should dispense with them for inefficient oars." But how do we know that the ancestors of Nessiteras ever had efficient hydrofoil limbs, and who is to measure the efficiency of their diamond-shaped flippers against the functions they have to perform? Evidently it is adequate for their mode of life.

It may be worth remembering that scores of species of some 53 genera of plesiosaurs are known to science from their fossil bones. In none of them is the skin contour of the head recorded in the stone, and only two examples show the skin contour of the flippers. In many cases the shapes of both birds' wings and fishes' fins vary widely within a single order.

Nor should we forget the processes of convergent evolution. Our paper describing Nessiteras said of the flipper "the inclination is to view it as reptilian." Nowhere in the paper was the name plesiosaur used.

The theory that the photographs depict the remains of a Viking ship does not fit the facts, even if the vessel were to be drifting round in midwater like a submerged Flying Dutchman. It is quite impossible, within a number of limiting circumstances, for the head photograph to be a stationary object attached to, or resting on the bottom. These limitations include the geometry of the camera, its strobe-flash equipment and the rope from which it was suspended from the boat, the distance and nature of the bottom below, and the turbidity of the water. On the other hand the Dragon head from Oseberg which they show may, in spite of its mammalian connotations, perhaps have been influenced by monsters well known to the Vikings.

The interpretation of the two pictures of the flipper as a rudder of a Viking ship is perhaps a measure of the inadequacy of modern newsprint reproduction. In the enlargements of the computer-enhanced photographs it is especially interesting that, in the interval of one minute between exposures in a camera standing stationary on the bottom, the flipper has changed shape and orientation. The changes are entirely consistent with the movement of an animal's swimming limb, and could not conceivably have happened if the object had been fixed and solid. These photographs were taken simultaneously with the moving objects shown in the sonar trace published with our article, which seem to have been conveniently ignored by your correspondents. They end with "an inescapable conclusion" from which they might do well to escape after all. If they are interested in Viking ships they will have to go elsewhere to find them. 